\title{
Does hypertension begin in adolescence?
}

Kyung Lim Yoon, MD, PhD

Department of Pediatrics, Kyung Hee University Hospital at Gangdong, Seoul, Korea

Hypertension is a major public health problem throughout the world as well as a leading cause of cardiovascular disease, which contributes to premature mortality. The prevalence of hypertension in adults is approximately $25 \%$ and is substantially increasing.

Pathophysiological and epidemiological studies have indicated that childhood blood pressure (BP) is closely associated with BP in later life.

Ironically, atherosclerosis beginning in youth was observed in the Korean War in which $77 \%$ of young United States soldiers killed in action had advanced atherosclerosis ${ }^{1)}$. In the Pathobiological Determinants of Atherosclerosis in Youth (PDAY) study, atherosclerosis was shown to be related to risk factors for heart disease in autopsied young subjects and was described as a pediatric problem, suggesting that controlling those risk factors in youth will prevent atherosclerosis and thereby prevent coronary heart disease later ${ }^{2}$. Data from another autopsy study, the Bogalusa Heart Study, showed that as the number of cardiovascular risk factors increases, the severity of asymptomatic coronary and aortic atherosclerosis increases in young people ${ }^{3)}$.

The national data from the Korean Centers of Disease Control in 2006 suggest that obesity prevalence in Korea is approximately $17.9 \%$ in 10- to 14-year-old male adolescents ${ }^{4)}$, surprisingly higher than that of the United States in the same period. Secular trends in obesity have been documented among American children, but the increases have decelerated since 19995). However, there have been few reports that describe the precise prevalence of obesity and related hypertension in Korea.

Obesity can raise BP by altering cardiac output, cardiac systolic and diastolic function, and renal-pressure natriuresis ${ }^{6}$. Moreover, obesity is associated with high arterial pressure through sympathetic nervous system and renin-angiotensin-aldosterone system activation as well as endothelial and renal dysfunction ${ }^{7}$.

In the current issue of this journal, Kim et al. ${ }^{8}$ provide us with various data regarding obesity-related indices as well as its hemodynamic determinants in 565 adolescents. They report that body mass index (BMI) had an independent positive correlation with systolic and diastolic BP because of its effects on stroke volume, cardiac output, and total arterial compliance, which are hemodynamic determinants of BP. In this report, they have performed laborious tasks to estimate these hemodynamic determinants and obesity-related indices as well as biochemical parameters in fasting blood samples. Children with abdominal obesity were defined as those at or above the 90th percentile of waist circumference (WC) for their specific age and gender. The weight-to-height ratio (WHR) was also proposed as a measure of abdominal adiposity in this study. However, this study did not report what percentage of obese adolescents had hypertension in this school-based cross-sectional study.

Obesity-related indices (BMI, WHR, and percent body fat) previously reported in a study of Chinese adolescents showed that BP increased from 2005 to 2010, which is consistent with the hypothesis that the increase in BP was partly attributable to an increase in BMI9). Hu et al. ${ }^{10)}$ showed that increased BMI, WC, and WHR were directly associated with high BP
Corresponding author: Kyung Lim Yoon, MD, PhD Department of pediatrics, Kyung Hee University Hospital at Gandong, 892 Dongnam-ro, Gandonggu, Seoul 137-727, Korea

Tel: $+82-2-440-7000$

Fax:+82-2-440-7175

Email: ykr3215@hanmail.net

Received: 10 October, 2013

Accepted: 29 October, 2013
Copyright (C) 2013 by The Korean Pediatric Society

This is an open-access article distributed under the terms of the Creative Commons Attribution NonCommercial License (http://creativecommons.org/ licenses/by-nc/3.0/) which permits unrestricted noncommercial use, distribution, and reproduction in any medium, provided the original work is properly cited. 
in 1,145 Chinese children and adolescents aged 7-17 years, and the prevalence was higher when increased BMI was combined with WC. In another large-scale school-based study of over 78,000 children and adolescents in China, BMI and WC were positively correlated with systolic and diastolic BP. Furthermore, WC was considered a more sensitive indicator than BMI, which indicates that central obesity has a much stronger association with risk of hypertension than general obesity (general body fatness) ${ }^{11)}$. They reported that $22.6 \%$ of children were overweight or obese as defined by BMI (19.2\% as defined by WC). In that study, BMI was the factor most strongly associated with hypertension, but in another study in 2012, neither mean nor high BP levels increased during a period in which the prevalence of obesity increased almost 3-fold ${ }^{12)}$. These contradictory results lead us to believe that there are many influencing factors associated with hypertension or high BP.

Diastolic BP measured by an automatic oscillometric method is not determined by the absence of sound as with a mercury sphygmomanometer. In many previous studies, diastolic pressure was measured on the fourth Korotkoff sound, but the true intra-arterial diastolic pressure seems to be between the fourth and fifth sounds. Moreover, the exact measurement of BP in children is not easy because of "white coat" hypertension, inadequate cuff size, and the difficulty of multiple measurements in a quiet environment. In this situation, 24-hour ambulatory BP monitoring may help to confirm hypertension.

Hypertension is defined as systolic or diastolic BP $\geq 95$ th percentile for a child's gender, age, and height on at least 3 occasions. BP should be measured beginning at 3 years of age during health maintenance visits. Clinicians must recognize those with BP in the upper range of the distribution according to gender, age, and height, so that adequate management can be provided.

Hypertension, one of the major risk factors for cardiovascular disease, is established early in life. With data from diverse populations in their meta-analysis, Chen and Wang ${ }^{13)}$ revealed strong evidence for BP tracking from childhood into adulthood; that is, childhood BP is associated with BP in later life, and early intervention is important. To understand the ability of BP tracking to predict future hypertension, knowledge of the prevalence of hypertension in the population is critical ${ }^{14)}$.

Prediction of adult hypertension requires a multifactorial approach that takes into account known childhood physical and environmental risk factors, family history of hypertension, and novel genetic variants ${ }^{15}$.

In the study of Kim et al. ${ }^{8)}$, it would have been better to include these environmental risk factors, including dietary factors or breastfeeding, family history of hypertension, and preterm birth. Additionally, future studies are needed that can track children and adolescents with high BP into adulthood in our country to evaluate whether early intervention to lower BP can decrease cardiovascular complications.
In a recent long-term follow-up study in Japan, a steeper increase in BMI during primary school led to an increase in BP in adolescence even if baseline BMI was low ${ }^{16)}$. Risk factors measured at younger ages were better predictors than risk factors measured concurrently with atherosclerosis assessment ${ }^{17)}$. Furthermore, the risk factors measured in childhood were associated with carotid intima-media thickness or coronary calcification measured up to 15 years later. There is evidence that a lifetime low-risk-factor profile dramatically lowers coronary heart disease incidence $^{2)}$. Thus, controlling the cardiovascular risk factors (plasma cholesterol and lipoproteins, smoking, hypertension, and obesity) in early life may be helpful to decrease adult cardiovascular disease.

Furthermore, atherosclerosis begins in childhood with fatty streaks, which progress to fibrous plaques in adulthood. Pediatricians should support control and prevention of risk factors in children via lifestyle modification ${ }^{18)}$.

This school-based cross-sectional study aimed to prevent adult hypertension by early detection and management of obesity, which is a major risk factor for hypertension in prehypertensive adolescents. A longitudinal study design would be apt for tracking these high-risk adolescents, which will require greater awareness of this issue as well as financial support.

\section{Conflict of interest}

No potential conflict of interest relevant to this article was reported.

\section{References}

1. Enos WF, Holmes RH, Beyer J. Coronary disease among United States soldiers killed in action in Korea; preliminary report. J Am Med Assoc 1953;152:1090-3.

2. McGill HC Jr, McMahan CA, Gidding SS. Preventing heart disease in the 21st century: implications of the Pathobiological Determinants of Atherosclerosis in Youth (PDAY) study. Circulation 2008;117: 1216-27.

3. Berenson GS, Srinivasan SR, Bao W, Newman WP 3rd, Tracy RE, Wattigney WA. Association between multiple cardiovascular risk factors and atherosclerosis in children and young adults. The Bogalusa Heart Study. N Engl J Med 1998;338:1650-6.

4. Korea Centers for Disease Control and Prevention. The Third Korea National Health and Nutrition Examination Survey (KNHANES III), 2005-Health Examination- Korea. Cheongwon: Korea Centers for Disease Control and Prevention, 2006:38-44.

5. Ogden CL, Carroll MD, Kit BK, Flegal KM. Prevalence of obesity and trends in body mass index among US children and adolescents, 1999-2010. JAMA 2012;307:483-90.

6. Hall JE, Brands MW, Henegar JR. Mechanisms of hypertension and kidney disease in obesity. Ann N Y Acad Sci 1999;892:91-107.

7. Rahmouni K, Correia ML, Haynes WG, Mark AL. Obesity-associated 
hypertension: new insights into mechanisms. Hypertension 2005; 45:9-14.

8. Kim NY, HongYM, Jung JW, Kim NS, Noh CI, Song YW. The relationships of body mass index, waist-to-height ratio, and body fat percentage with blood pressure and its hemodynamic determinants in Korean adolescents: a school-based study. Korean J Pediatr 2013;56:526-33.

9. Dong B, Wang HJ, Wang Z, Liu JS, Ma J. Trends in blood pressure and body mass index among Chinese children and adolescents from 2005 to 2010. Am J Hypertens 2013;26:997-1004.

10. Hu YH, Reilly KH, Liang YJ, Xi B, Liu JT, Xu DJ, et al. Increase in body mass index, waist circumference and waist-to-height ratio is associated with high blood pressure in children and adolescents in China. J Int Med Res 2011;39:23-32.

11. Lu X, Shi P, Luo CY, Zhou YF, Yu HT, Guo CY, et al. Prevalence of hypertension in overweight and obese children from a large school-based population in Shanghai, China. BMC Public Health 2013;13:24.

12. Freedman DS, Goodman A, Contreras OA, DasMahapatra P, Srinivasan SR, Berenson GS. Secular trends in BMI and blood pressure among children and adolescents: the Bogalusa Heart Study. Pediatrics 2012;130:e159-66.

13. Chen X, Wang Y. Tracking of blood pressure from childhood to adulthood: a systematic review and meta-regression analysis. Circulation 2008;117:3171-80.

14. Gidding SS. Measuring children's blood pressure matters. Circulation 2008;117:3163-4.

15. Juhola J, Oikonen M, Magnussen CG, Mikkila V, Siitonen N, Jokinen E, et al. Childhood physical, environmental, and genetic predictors of adult hypertension: the cardiovascular risk in young Finns study. Circulation 2012;126:402-9.

16. Kuwahara E, Asakura K, Nishiwaki Y, Komatsu H, Nakazawa A, Ushiku $\mathrm{H}$, et al. Steeper increases in body mass index during childhood correlate with blood pressure elevation in adolescence: a long-term follow-up study in a Japanese community. Hypertens Res 2013 Sep 12 [Epub]. http://dx.doi.org/10.1038/hr.2013.109.

17. Li S, Chen W, Srinivasan SR, Bond MG, Tang R, Urbina EM, et al. Childhood cardiovascular risk factors and carotid vascular changes in adulthood: the Bogalusa Heart Study. JAMA 2003;290:2271-6.

18. McGill HC, McMahan CA, Gidding SS. Are pediatricians responsible for prevention of adult cardiovascular disease? Nat Clin Pract Cardiovasc Med 2009;6:10-1. 